\title{
A ambiguidade no discurso de Cléon sobre Mitilene: entre historiografia e comédia antiga ${ }^{1}$
}

\section{Ambiguity in Cleon's Discourse on Mytilene: Between Historiography and the Attic Comedy}

Felipe Campos de Azevedo

Universidade de São Paulo, São Paulo, São Paulo / Brasil

felipe.campos.azevedo@gmail.com

Resumo: Este breve estudo pretende comparar a imagem de Cléon traçada por Tucídides no início de seu discurso sobre a batalha de Mitilene (3. 37-39) com alguns testemunhos cômicos selecionados que tratam sobre o mesmo personagem, dentre as obras de Aristófanes e também de outros poetas da comédia antiga, como Êupolis, Hermipo e Platão cômico. Nesse discurso de Cléon reconstruído por Tucídides darei ênfase ao uso de determinado vocabulário que se aplica mais diretamente ao âmbito retórico, mas que encontra paralelos marcantes com o vocabulário usado em geral na comédia ática, e sobretudo no discurso parabático, de tom mais autoral. Por fim a minha intenção será contrastar não apenas a descrição geral de Cléon como um demagogo em ambos os gêneros, historiografia e comédia, mas lidar com conceitos ambíguos que aparecem no discurso do político, que critica os seus opositores como pretensos intelectuais através do uso de uma série de adjetivos ( $\sigma 0 \varphi o ́ \varsigma, ~ \delta \varepsilon \xi$ tó $, \lambda \varepsilon \pi \tau o ́ \varsigma, ~ \sigma 0 v \varepsilon \tau o ́ \varsigma)$. Esses conceitos são encontrados em profusão também no registro cômico, e com a mesma polissemia peculiar a esses termos, de modo que uma comparação de seus usos entre os gêneros pode ser bem delineada tomando a figura $\mathrm{e}$ o discurso de Cléon em Tucídides como fio condutor.

Palavras-Chave: Cléon; historiografia; comédia ática.

\footnotetext{
${ }^{1}$ Agradeço à FAPESP por financiar o meu mestrado em Letras Cássicas na USP eISSN: 1983-3636
} 
Abstract: This brief study intends to compare the image of Cleon drawn by Thucydides at the beginning of his discourse on the battle of Mytilene (3. 37-39) with some selected comic testimonies that deal with the same character by Aristophanes and other Old Comedy poets, such as Eupolis, Hermippus and Plato Comicus. I will analyze this thucydidean version of the discourse of Cleon, emphasizing the use of certain concepts that are more directly applied to rhetorical vocabulary but that find striking parallels with the vocabulary commonly used in Attic comedy, and especially in parabatic discourse, with a more authorial tone. I intend, above all, to establish a contrast between the general description of Cleon as a demagogue both in historiography and in comedy and the ambiguous concepts that appear in his discourse, in which he criticizes his opponents as so-called intellectuals through the use of a series of adjectives such as $\sigma 0 \varphi o ́ \varsigma, \delta \varepsilon \xi$ ló $\zeta, \lambda \varepsilon \pi \tau o ́ \varsigma, ~ \sigma v v \varepsilon \tau o ́ \varsigma$. These concepts are found in profusion also in comedy, and with the same peculiar polysemy. Therefore, a comparison of their uses in the two different genres in which they appear in abundance can be well delineated if one takes the figure and the discourse of Cleon in Thucydides as the guiding thread of a research, as I intend to do in this paper.

Keywords: Cleon; historiography; Attic Comedy.

Recebido em: 2 de fevereiro de 2017.

Aprovado em: 17 de julho de 2017.

\section{Introdução}

É sobretudo em Cavaleiros, de 424 a.C., que temos a imagem de Cléon caracterizada por Aristófanes como um tipo demagógico e populista, por meio de seu personagem Paflagônio, que levava a cidade à ruina com sua política externa belicista. Essa crítica velada ao político é reflexo da polêmica gerada dois anos antes na peça de sua autoria Babilônios, de 427 a. C., pela qual o poeta teria sofrido uma acusação judicial por ter exposto o alvo de crítica ao ridículo diante de um público 
estrangeiro em pleno contexto da guerra do Peloponeso, e estaria dessa forma fornecendo munição aos seus rivais espartanos de Cléon (Acarnenses, v. 502-505). ${ }^{2}$ A contenda com o político, que aparece logo no início da carreira do poeta, continua presente durante grande parte da produção posterior do comediógrafo, e podemos ainda ver a presença de Cléon em Vespas, de 422 a.C, servindo como radical ao nome dos protagonistas Bdelicléon (o que odeia Cléon) e Filocléon (o que ama Cléon), com ampla citação durante todo o enredo. ${ }^{3}$ Já na parábase de Nuvens (v. 549 ss.), de 423 a.C., ${ }^{4}$ o coro diz que só atacou o político quando este estava em evidência, ao contrário de seus rivais, que o faziam quando ele já tinha caído em descrédito - mas mesmo após sua morte, na batalha de Anfípolis (Tucídides 5.6-11), Cléon continua sendo alvo de escárnio em $P a z$ (v. 47), de 421 a.C., assim como em Rãs (v. 559, 577), em 405 a.C. Apesar de todo esse rico material, ao invés de proceder a uma verificação mais profunda da figura de Cléon em Aristófanes, pretendo examinar outras fontes cômicas importantes sobre o político ateniense que são menos conhecidas mas que contribuem igualmente para uma comparação posterior com o registro historiográfico de Tucídides. A partir de alguns fragmentos de poetas cômicos como Êupolis, Hermipo e Platão cômico, aliados a passagens selecionadas da obra de Aristófanes, pretendo cotejar as semelhanças e diferenças de caracterização de Cléon de um gênero para outro, e sobretudo alguns termos empregados pelo político no seu discurso sobre Mitilene reconstruído por Tucídides, e examinar como esses mesmos conceitos são utilizados no gênero cômico.

\section{Testemunhos cômicos}

Começo por um fragmento de Êupolis identificado como pertencente à peça $A$ raça de ouro, datada usualmente de 429 a.C. a 422 a. C., ${ }^{5}$ e provavelmente pertencente à parte da parábase: ${ }^{6}$

Ó cidade mais bela dentre todas as que Cléon supervisionou,

\footnotetext{
${ }^{2}$ Sobre a presença em Acarnenses cf. v. 6, 300, 377, 502, 659.

${ }^{3}$ Cf. Vespas v. 62, 133, 137, 163, 197, 242, 342, 372, 409, 596, 759, 1220, 1224, 1237, $1285,1466$.

${ }^{4}$ Embora a versão que possuímos é sem dúvida uma versão posterior da apresentada em 423 a. C., revisada em algumas partes.

${ }^{5}$ Cf. Storey (2003, p. 266).

${ }^{6}$ Cf. Olson (2007, p. 212).
} 
como era bem-aventurada antes e será ainda mais agora.

$[\ldots]$

Pois, primeiro, é preciso começar com igualdade de discurso para todos.

$[\ldots]$

Então como alguém não se alegraria de se unir a esta cidade, já que nela é possível a alguém tão frágil e feio na aparência $[. . .]^{7}$

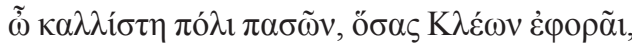

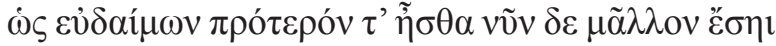

$[\ldots]$

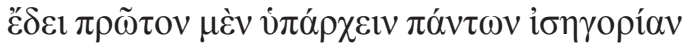

$[\ldots]$

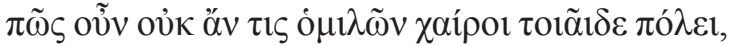

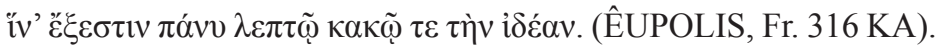

A primeira impressão que se tem pelo título da peça é a lembrança de Hesíodo (Trab. 109 ss.), com a definição dessa geração de ouro como a primeira e mais antiga dos homens, uma espécie de paraíso perdido. No entanto, essa temática, da utopia de um tempo antigo ou futuro, não é estranha ao gênero da comédia antiga, figurando sem tanto relevo nas comédias que restaram intactas de Aristófanes, tendo papel marcante somente em Aves, mas incorporada como um tema recorrente do gênero cômico da segunda metade do século V a.C. ${ }^{8}$ em alguns rivais mais velhos do dramaturgo (Cratino, Crates e Ferécrates) ${ }^{9}$. Inesperadamente, nesse fragmento de Eupolis, a temática da utopia de um tempo perdido ou vindouro é na verdade localizada no próprio presente, na Atenas dos anos vinte do século V a.C. Como esses versos mostram, a cidade democrática e imperial da época figura como

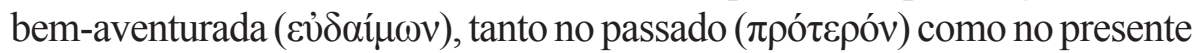
(vข̃v) e, talvez ironicamente, como possível de sê-lo ainda mais nos anos que viriam ( $\left.\mu \tilde{\alpha} \lambda \lambda \mathrm{\gamma} v \varepsilon^{\sigma} \sigma \eta \imath\right)$. Até os primeiros dois versos, quando há uma lacuna, Atenas aparentemente é louvada pelo seu domínio político sobre as

\footnotetext{
${ }^{7}$ Todas as traduções, quando não indicado em nota, são de minha autoria.

${ }^{8}$ Cf. Storey (2011, p. xxi-xxii).

${ }^{9}$ Cf. Cratino fr. 171, 172, 176 K-A; Crates ffr. 16, 17 K-A; Ferécrates fr. 113 K-A.
} 
demais cidades, mas a sequência desses versos mostra o tom irônico dessa louvação, já que nesta cidade é possível aos frágeis/fracos ( $\lambda \varepsilon \pi \tau \tilde{\varphi})$ e feios/

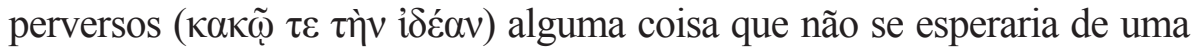
cidade tão perfeita, e que seria, provavelmente, o fato de figurar entre os principais líderes alguém como Cléon. ${ }^{10}$

A figura desse político, inserida em uma comédia, não deixa dúvidas do tipo de governante a que Êupolis se refere, lembrando a forma como ele é materializado em Aristófanes, ou ainda, em mais um sugestivo fragmento (fr. $331 \mathrm{~K}-\mathrm{A}$ ) do próprio Êupolis sobre o mesmo político:

Pois foste o primeiro para nós, ó Cleon,

a dizer para nos alegrarmos, enquanto causavas muitas dores à cidade.

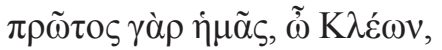

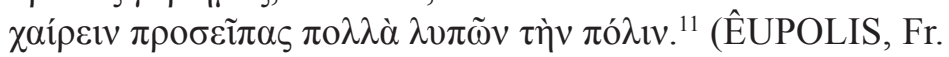
$331 \mathrm{~K}-\mathrm{A})$

Além de Aristófanes e Êupolis, poetas mais famosos que integram o trio canônico da comédia antiga ao lado de Cratino, Cléon também é alvo de comédiografos como Hermipo e Platão cômico. Esse último, Platão cômico (fr. $115 \mathrm{~K}-\mathrm{A}$ ), inclusive, diz ter sido o primeiro a confrontá-lo nos palcos:

Pois eu fui o primeiro a iniciar uma guerra contra Cléon.

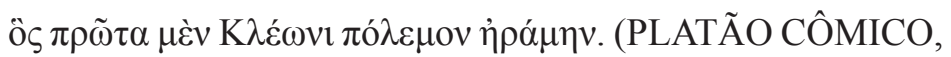
Fr. $115 \mathrm{~K}-\mathrm{A})$.

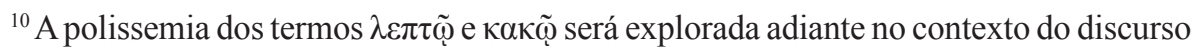
de Cléon em Tucídides, e até por isso é proposta mais de uma possibilidade de tradução para cada termo. O adjetivo $\lambda \varepsilon \pi \tau$ ó $\varsigma$ costuma se referir no discurso cômico a algo "sutil", "sofisticado" de forma abstrata ou algo mais concreto como "frágil", "fino" e "delicado". Já em relação a אakós poder-se-ia tomá-lo tanto no sentido físico de "feio", quanto pelo atributo moral de "perverso", "maldoso", mas aqui a complementação do acusativo de

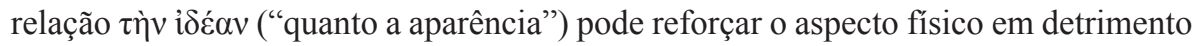
do moral. Justamente por nos apoiarmos em técnicas como a da polissemia e outros jogos de palavra, será importante, para considerar a comédia, tratarmos com todas as acepções possíveis, podemos, entretanto, vislumbrar pelo contexto o que é mais adequado caso a caso. Para o uso da polissemia na comédia cf. Wrigth (2012, p. 25). ${ }^{11}$ Esse fragmento lembra em muito um slogan do atual presidente interino da nação, que diz: "Não pense em crise, trabalhe".
} 
Já Hermipo (fr. $47 \mathrm{~K}-\mathrm{A}$ ) parece se referir à sucessão de gerações simbolizada na passagem do comando de Péricles para Cléon:

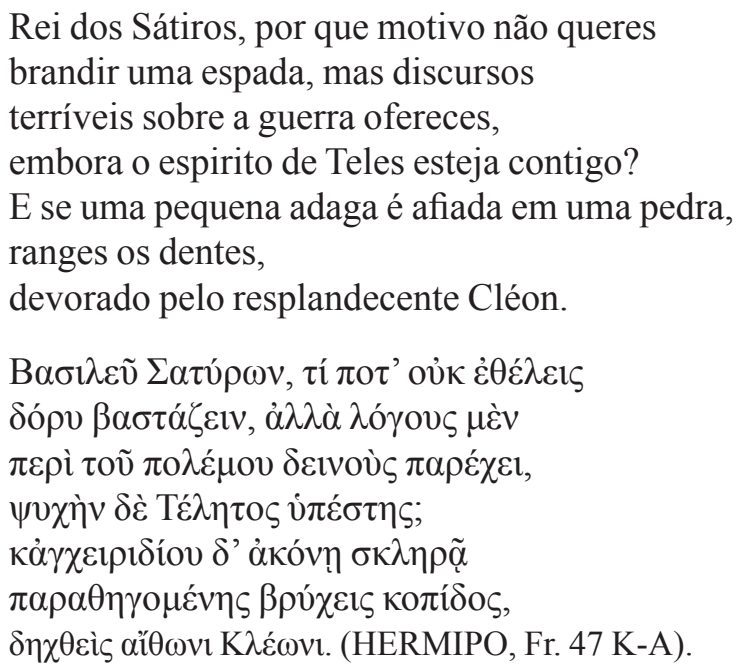

Embora Péricles não esteja nomeado, a exegese da passagem costuma identificar o general com Dioniso, mencionado no primeiro verso como "Rei dos Sátiros" (B $\alpha \sigma \imath \lambda \varepsilon v ̃ ~ \Sigma \alpha \tau u ́ \rho \omega v)$, com base na relação com a peça Dionisoalexandros, de Cratino, na qual o deus representaria ao mesmo tempo Páris e Péricles, em uma paródia mítico-burlesca da guerra de Troia contrastada ao cenário político da democracia ateniense. ${ }^{12}$ A identificação de Péricles é mais clara na sequência, pela mencionada

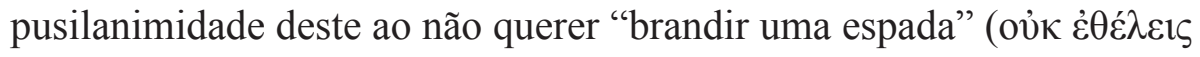

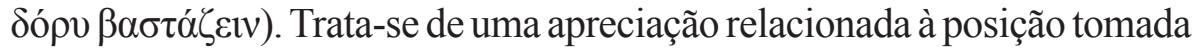
pelo general no início da guerra, interpretada como hesitação covarde pela população após a invasão dos espartanos, segundo o testemunho de Tucídides (2.21.2-3), por orientar que os cidadãos não revidassem os ataques sofridos, mas adotassem uma postura cautelosa recomendada por Péricles, e aprovada por Tucídides. Em oposição ao primeiro, que se recusa a pegar em armas e se caracteriza por seus "discursos" ( $\lambda$ ó $00 \varsigma$ ), Cléon é descrito como um cão que "devora" ( $\delta \eta \chi \theta \varepsilon i \varsigma)$ suas presas. Essa

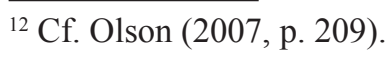


caracterização de Cléon como um ser agressivo em oposição à moderação de Péricles será central também para Tucídides, que descreve o primeiro

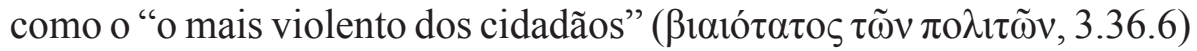
enquanto o segundo é qualificado como "o mais capaz em falar e agir"

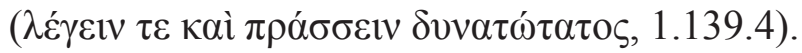

\section{O discurso de Cléon sobre Mitilene em Tucídides e os ecos cômicos}

Além de figurar em Aristófanes e em outros poetas cômicos, Cléon aparece como personagem importante em Tucídides, sendo o líder de uma política imperialista, sobretudo depois do sucesso obtido sob seu comando em Pilos, em 425 a.C. Ao compararmos o papel de relevo que é atribuído a Cléon tanto na comédia antiga quanto na obra de Tucídides, é possível traçar alguns paralelos esclarecedores sobre esse político, particularmente no que se refere a sua atuação durante esse período, do qual datam cinco das onze comédias que nos restaram intactas de Aristófanes (Acarnenses, Cavaleiros, Nuvens, Vespas e Paz). ${ }^{13}$ Tomarei como corpus apenas o começo do discurso de Cléon reconstruído por Tucídides no livro 3 da História da Guerra do Peloponeso, em que o político sustenta veementemente o massacre da população masculina de Mitilene (3.37-40), que acabara de ser tomada pelos atenienses, em 427 a.C. Nesse discurso Cléon começa com uma crítica aberta ao regime democrático, ao dizer que sempre o julgou incompatível com um império, como era o ateniense, e confirma esse seu pensamento naquele momento em que ocorre a mudança de opinião dos atenienses sobre a pena infligida aos mitilênios, dando perdão àqueles que antes haviam condenado à morte $(3.37 .1$ - 2).

Já muitas vezes e por outras ocasiões eu pessoalmente reconheci que a democracia é incapaz de governar outros, sobretudo num caso, como este é, de uma mudança de atitude da vossa parte em relação a uma situação como a de Mitilene. Pelo facto de no dia-

\footnotetext{
${ }^{13}$ Respectivamente de 425 a.C. até 421 a.C. Deve-se fazer uma ressalva a Nuvens, cuja produção original data de 423 a.C., mas o texto que possuímos é uma reescrita posterior. Cf. Dover (1968).
} 
a-dia tudo se passar sem receios nem suspeitas no que respeita as vossas relações em comum, o mesmo sentis em relação aos vossos aliados, e, deixando-vos convencer pelas suas palavras sois por eles enganados e se cedeis à compaixão, não é sem perigo que assim pensais, no que vos diz respeito, nem tão pouco granjeais a gratidão dos mesmos. Não conseguis ver que é tirania o poder que sobre eles exerceis e que, sempre intrigando contra vós, são eles comandados por vós contra a sua vontade, e não é por serem beneficiados por vós com prejuízo vosso que vos obedecem, mas mais pelo poder que exerceis do que pela sua vontade. ${ }^{14}$

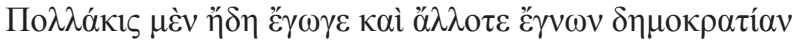

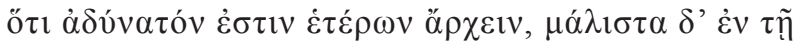

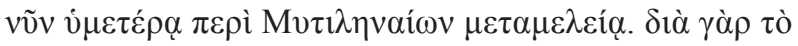

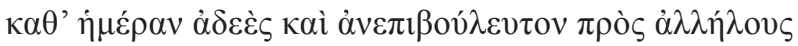

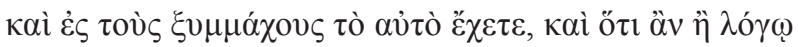

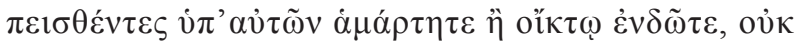

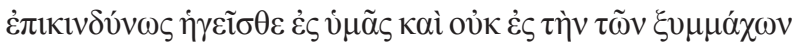

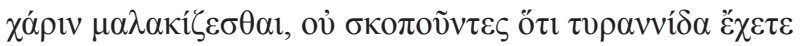

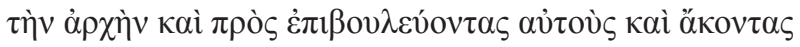

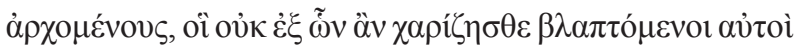

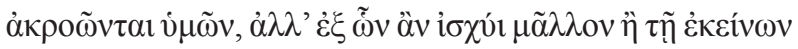

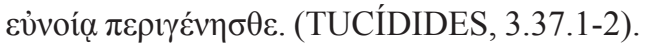

Na visão do político a fraqueza do povo o expõe a perigos, e para sanar as dificuldades impostas pelas escolhas equivocadas da população, ele chega a comparar o império ( $\dot{\alpha} \rho \chi \eta ̀ v)$, liderado por Atenas sobre outras cidades, a uma tirania ( $\tau \nu \rho \alpha v v i ́ \delta \alpha$ ) - já que na visão deste é pelo medo do poderio de Atenas que suas colônias, como Mitilene, a obedecem e não por uma disposição própria e cooperativa. A comparação do império ateniense com uma tirania não é nova, e no livro II Tucídides já colocara

\footnotetext{
${ }^{14}$ Tradução de Rosado Fernandes e Granwehr (2010, p. 281). Todas as demais traduções de excertos de Tucídides utilizados neste trabalho seguem a mesma tradução indicada aqui.
} 
na boca de Péricles essa mesma comparação em um de seus discursos (2.63-2). Não apenas Tucidides já havia notado essa semelhança, como Cratino (fr. $258 \mathrm{~K}-\mathrm{A}$ ) já havia ido inclusive mais longe, comparando o próprio Péricles, individualmente, a um tirano, ${ }^{15}$ assimilado dessa vez não a Dioniso, mas à figura de Zeus:
A revolta e o velho Cronos
uniram-se um ao outro
e geraram o maior dos tiranos,
o qual de junta-cabeças
é chamado pelos deuses.

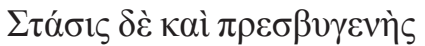

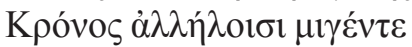

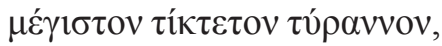
ôv $\delta \grave{\eta े ~ \kappa \varepsilon \varphi \alpha \lambda \eta \gamma \varepsilon \rho \varepsilon ́ \tau \alpha ~} \alpha$

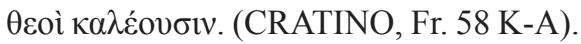

Em Cratino ele é relacionado ao rebento de Cronos, que teria

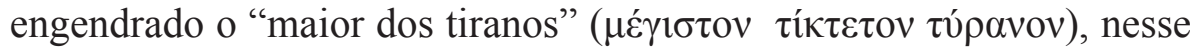
caso não Zeus, mas o próprio Péricles, identificado por sua cabeça avantajada, ao ser chamado de junta-cabeças ( $\varepsilon \varphi \alpha \lambda \eta \gamma \varepsilon \rho \varepsilon ́ \tau \alpha \nu)$, tendo como molde um epíteto famoso do deus olímpico, o junta-nuvens ( $\varepsilon \varepsilon \varphi \varepsilon \lambda \eta \gamma \varepsilon \rho \varepsilon ́ \tau \eta \varsigma)$. A comparação de Péricles com Zeus pode ser encontrada no mesmo sentido em uma passagem de Acarnenses (v.530-34), quando o político é chamado de "olímpico" e acusado de impor sobre os gregos

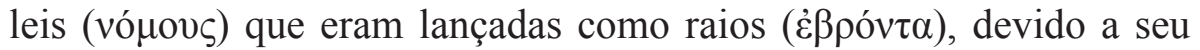
comando austero e autoritário:

Irritado, Péricles, o Olímpico, lançou o raio, fez ouvir o trovão, pôs a Grécia em polvorosa e estabeleceu leis rígidas à maneira de cantilenas.

\footnotetext{
${ }^{15}$ Cléon não é explicitamente comparado a um tirano, como Péricles, mas foi também igualado comicamente a um deus: se Péricles foi comparado a Zeus na comédia antiga, o próprio Cléon é em uma passagem anônima (Adesp. $461 \mathrm{~K}-\mathrm{A}$ ) comparado a Prometeu

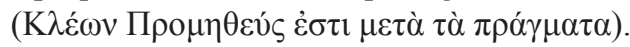




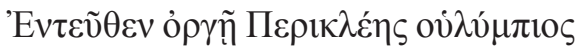

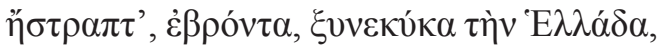

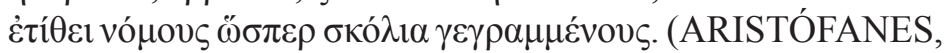
Acarnenses, v. 530-34). ${ }^{16}$

Já em Tucídides é usualmente a cidade democrática e imperial de Atenas que serve como uma metáfora da tirania, e não um indivíduo em particular. No entanto, o problema dessa posição tirânica de Atenas é que os beneficiários desse poder não são os cidadãos que compõem a cidade, mas justamente os demagogos que, como Cléon, expõem a população a uma guerra em proveito de suas ambições pessoais. Isso fica muito bem caracterizado em diversas comédias de Aristófanes, das quais Cavaleiros é o melhor exemplo, com o embate entre dois demagogos paradigmáticos, como o Salsicheiro e o Paflagônio. Isso pode ser sentido ainda em diversas outras obras cômicas, tanto de Aristófanes quanto de seus rivais, e em um ensaio recente em que Henderson (2003, p. 159) examina a questão da tirania, uma passagem é útil para contrastar com a imagem usada no discurso de Cléon:

One constant and central theme of the comic take on tyrany is this: the Atenian demos held and reserved to hold arguably tyrannical power at home and abroad, but the beneficiary of that power was not the demos but dishonest demagogues; and it was the demagogues, not the demos, who deserved blame for misuse of that power. In short, the comic poets involved themselves in the political battle between populist leaders and their elite opponents that was being waged before the sovereign demos. It was a battle about leadership, at the ambivalent ideology of tyranny was one of the weapons. (HENDERSON, 2003, p. 159).

Prosseguindo na exegese do debate sobre Mitilene, o discurso inflamado de Cléon vai além de descrever o império ateniense como uma tirania, e afirma que nesse cenário instável são preferíveis cidadãos sem

${ }^{16}$ Tradução de Maria de Fátima Sousa e Silva (1988, p. 58). 
inteligência ( $\alpha \mu \alpha \theta i ́ \alpha)$, mas dotados de bom senso ( $\mu \varepsilon \tau \grave{\alpha} \sigma \omega \varphi \rho \circ \sigma u ́ v \eta \varsigma)$, do

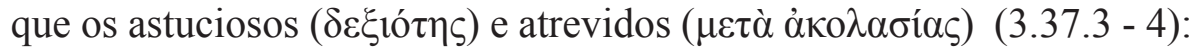

O pior de tudo é que, se nada do que decidirmos, nos nossos planos, tiver bases duráveis, por não reconhecermos que um Estado que dispõe de leis inferiores e invioláveis é mais forte do que um que as tenha melhores mas sem autoridade; que a ignorância na companhia de algum bom senso é de maior utilidade que a competência acompanhada de pouco discernimento, e que homens com menos inteligência em relação aos mais capazes são, na maior parte das vezes, melhores cidadãos.

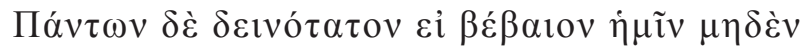

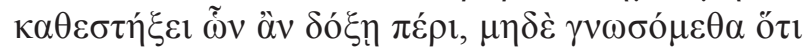

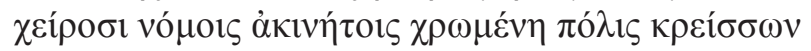

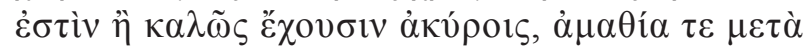

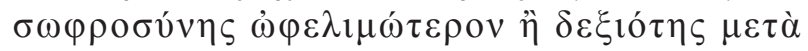

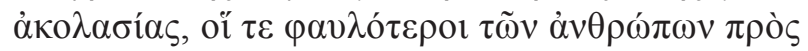

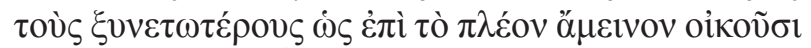

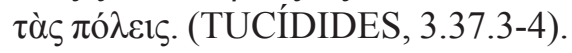

A acusação de Cléon contra aqueles pretensamente mais sábios vai no mesmo sentido da sátira de Hermipo (fr. $47 \mathrm{~K}-\mathrm{A}$ ), tendo Péricles em vista quando condena aqueles que são capazes de convencer a população por meio de um discurso bem ordenado, recordando a forma como Péricles agira no início da guerra, recomendando a cautela antes da ação - enquanto Cléon nesse momento propõe justamente o oposto, que a população não reconsidere suas decisões em relação a Mitilene, e atue de forma ofensiva. Ocasionalmente ou não, a forma como Cléon descreve esses oradores da época, como dotados de astúcia ( $\delta \varepsilon \xi$ ió $\tau\rceil \zeta)$, é paralela à imagem que Aristófanes constrói da sua poesia, sobretudo nas parábases de Nuvens e Vespas. ${ }^{17}$ Temos um exemplo ilustrativo em Nuvens (v. 521),

${ }^{17} \mathrm{O}$ termo $\delta \varepsilon \xi ı ́ \varsigma \varsigma$ parece ter papel proeminente em Aristófanes, e como comentado por Silk (2000, p. 46), pode ser visto como uma das caraterísticas principais para definir a

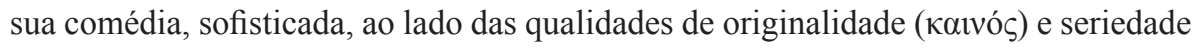


em que o poeta diz que considerava seus espectadores "astuciosos" ( $\mu \tilde{\alpha} \varsigma$

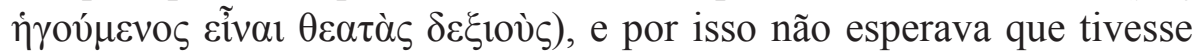
sido derrotado naquele concurso; ou ainda na mesma parábase, quando o poeta, na pele do coro, diz que nunca trairia os “astuciosos" (oủ $\delta$ ' $\hat{\omega} \zeta$

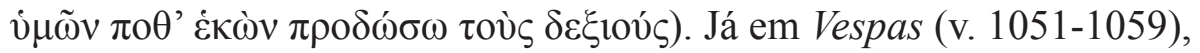
ao alertar os espectadores sobre as qualidades da sua poesia, Aristófanes diz que eles devem escolher os poetas mais inovadores (Katvóv) como

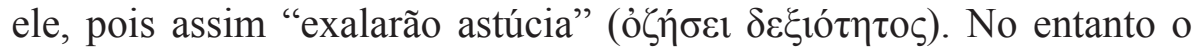
termo também aparece conectado de forma irônica a poetas e filósofos ridicularizados por sua conduta arrogante, como pretensos sábios que pairam acima dos homens comuns. ${ }^{18}$ Nesse sentido Wright (2012, p. 25) nota com agudeza a polissemia do termo no contexto ateniense do final do século V a.C. e o modo como essa característica passa de algo laudatório na poesia épica e arcaica a uma característica duvidosa durante a ascensão de oradores falaciosos:

Wisdom or knowledge, in a broad sense, had long been seen as characteristic attributes of poets, whose function, as we have already seen, might be thought to include an explicit didactic or moralizing role. But in the last few decades of the fifth century, sophos and dexios seem to have subtle altered their meanings, so as to denote, among other things, a new sort of wit or sophistication - the sort of quality, in fact, embodied

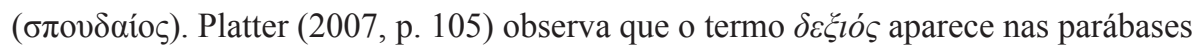
de Vespas e Nuvens, em uma quantidade não usual, se comparado com sua ocorrência no restante do corpus aristofânico, demostrando a importância desse conceito nesse momento da carreira do autor, que coincide justamente com o momento da batalha de Mitilene, em meados da década de 20 do século V a.C. Platter (2007, p. 105) traz uma quantificação proporcional do termo nessas passagens, relacionando-o às aspirações do poeta: "in all three passages (the two parabaseis and the speech of Xanthias), there is a proliferation of words having to do with cleverness, comprehension, sense, and recognition - all attesting to the shared aspirations of Clouds and Wasps. Such words, of course, abound in Aristophanic comedy, but they appear with a quite unusual frequency here. In the ninety-four lines with which we are concerned, forms of $\delta \varepsilon \xi$ l- appear at a rate of 53.19 per thousand lines, as opposed to the rest of the corpus of extant plays, in which they appear at a rate of only 3.50 per thousand".

${ }^{18}$ Materializada na imagem de Sócrates em Nuvens (v. 226) pendurado em uma cesta à maneira de um deus ex machina. 
by the sophists (whose very name implies an abundancy of sophia) (WRIGHT, 2012, p. 25, grifos do autor)

Embora o embate entre Cléon e os comediógrafos não seja em nenhum momento da obra comentado por Tucídides, ao analisar os alvos desse discurso, poderíamos talvez colocar entre eles o próprio Aristófanes, assim como outros poetas dessa nova geração, que igualmente o atacaram. ${ }^{19}$ Corrobora esse paralelo o fato de que a imagem feita do político na comédia caminha muito mais para o lado da violência e da agressividade do que para a sutileza e a inteligência. Um exemplo disso é a descrição do personagem Paflagônio, que é a caricatura de Cléon em Cavaleiros (v. 1017), qualificado como um "cão com dentes afiados"

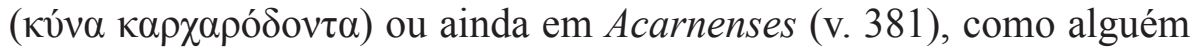

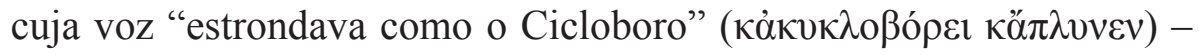
paralelo nesse sentido à descrição de Tucídides do mesmo Cléon como

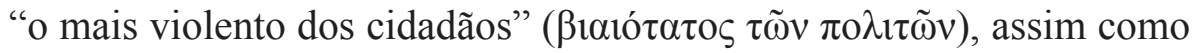
a descrição de Hermipo (fr. $47 \mathrm{~K}-\mathrm{A}$ ), de um cão que "morde" ( $\delta \eta \chi \theta \varepsilon i \varsigma \varsigma)$ seus adversários - e novamente a imagem canina do político em Vespas (v. 971-72), durante o julgamento do cão Labes.

$\mathrm{Na}$ continuação de seu discurso Cléon ainda diz que as cidades são mais bem governadas por "homens simples" ( $\propto \alpha v \lambda$ ó $\varepsilon \rho \circ)$ do que

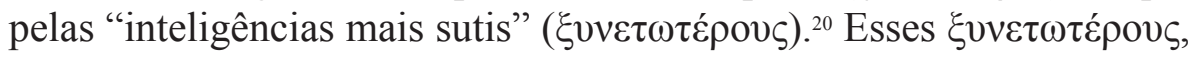

${ }^{19}$ Já a relação da comédia antiga com Heródoto foi levantada por diversos críticos, entre eles Nesselrath (2013, p. 344), mas nesse caso como uma apropriação por parte de Aristófanes das Histórias, ao invés dessa relação que estaria invertida, no caso de Tucídides, com a historiografia se apropriando da comédia, ou pelo menos tratando de temas comuns do mesmo momento. No caso de Heródoto são apenas duas passagens de Aristófanes que fariam referência às Histórias, uma delas em Acarnenses (524-9) na qual a relação se estabeleceria por atribuir a causa dos atritos com Mégara ao roubo de duas mulheres (cortesãs), como Heródoto faz no famoso início de sua obra, atribuindo a causa dos desentendimentos que resultaram na guerra de Troia aos raptos de mulheres (princesas), desde Io, Europa e Medeia até Helena - a ironia paira portanto na posição social distinta dessas mulheres raptadas, prostitutas ou princesas.

${ }^{20}$ Hornblower (1991, p. 244) comenta que ovvetós é usado em Tucídides normalmente em sentido positivo, de "prudência" e "inteligência", sentido que será resgatado na resposta de Diodoto a Cléon, e que deixa mais uma vez entrever a aversão do 


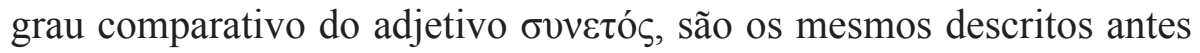
como $\delta \varepsilon \xi$ ió $\varsigma$, mantendo-se como alvo da detração dos oradores (e talvez dos poetas) que se apregoavam este tipo de inteligência "sutil" e "refinada" - o que também muitas vezes aparece caracterizado a partir do adjetivo $\lambda \varepsilon \pi \tau$ óv, aplicado a Cléon no fragmento visto de Êupolis (fr. $316 \mathrm{~K}-\mathrm{A}$ ), e encontrado recorrentemente em Aristófanes para descrever essa casta intelectual. ${ }^{21}$ Esse termo também figura na comédia dentro do mesmo campo semântico dos já citados, e neste caso podemos ver Eurípides e Ésquilo n' As rãs (876-878) descritos ao mesmo tempo como

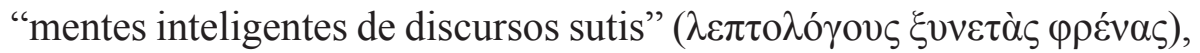
e na mesma peça o próprio Eurípides louva a $\Xi v ́ v \varepsilon \sigma ı \varsigma$ como uma das divindades por ele cultuadas. ${ }^{22}$

Para além dos termos usados para qualificar os seus antagonistas é de se notar também a menção feita às leis (vó $\mu \omega v)$ e como esses pretensiosos oradores são acusados de não as respeitarem (3. 37.4).

Os que pretendem demostrar que são mais sábios do que as leis, e que sempre querem prevalecer nas reuniões públicas em que falam, como se não houvesse outros factos mais importantes em que possam fazer vingar a sua opinião, por motivos dessa ordem, na maior parte das vezes arruínam os Estados.

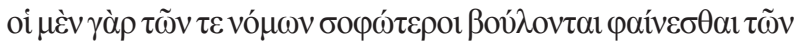

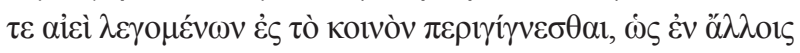

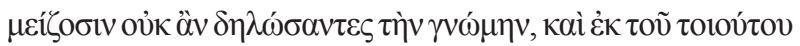

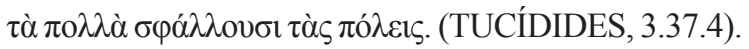

Um fato histórico conhecido na relação de Cléon com os poetas cômicos diz respeito diretamente a essas questões legais, tendo sido Aristófanes processado pelo político por tê-lo ridicularizado em sua comédia

historiógrafo ao político ateniense, que nega e condena características que na maioria das vezes deveriam ser louvadas.

${ }^{21}$ Sobretudo em Nuvens, para caracterizar a linguagem socrática, e em Rãs, para as falas de Eurípides.

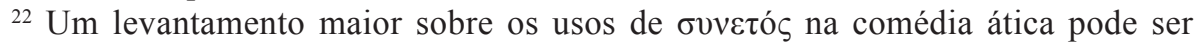
encontrado em Jedrkiewicz (2013, p. 344). 
Babilônios. Essa acusação pode ser vista em uma referência em Acarnenses (v. 502-505), quando na parábase o poeta toma a voz e fala ao público:

Desta vez Cléon não pode me acusar de falar mal da cidade na presença de estrangeiros. Estamos sós, este é o concurso das Leneias, não há estrangeiros presentes. $^{23}$

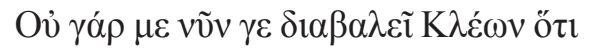

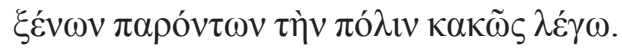

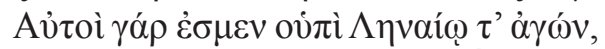

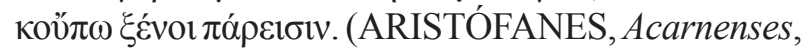
v. 502-505).

Esses processos provavelmente se baseavam em uma série de decretos, que podem ser inferidos por um escólio em Acarnenses $(\Sigma$ Acarn. 67), o qual diz que durante o período em que Moriquines foi arconte (440/439) se passou uma lei proibindo a exposição ao ridículo de figuras públicas, que teria durado durante o governo de Glauquinos (439/438) e Teodoros (438/437). Mas, como Aristófanes só começa sua carreira nos anos 20, sendo Acarnenses de 425, teríamos que rastrear as motivações da época para esse suposto processo. Dobrov (2010, p. 346) esclarece que houve ainda nesse sentido um decreto de Antímaco (426/7) inferindo, dessas evidências cômicas uma "lei de Cléon" (meados de 420),

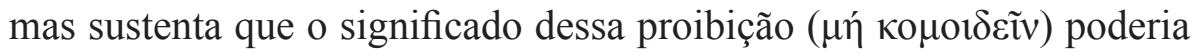

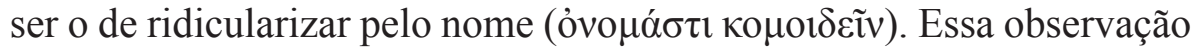
coaduna com a acusação acima, que se baseava na afirmação de que ele havia sido ridicularizado explicitamente na frente de estrangeiros (que indica a exibição de Babilônios no concurso das Grandes Dionisíacas, festival internacional, no qual estavam presentes não apenas os atenienses, e não nas Leneias, festival de caráter mais doméstico).

No entanto, o poeta não se furtou em nenhum momento a expor a sua sátira do político nos anos que se seguiram, e os problemas relativos à existência de uma censura ou não aos poetas já foi um assunto de muito debate pelos estudiosos. Um bom resumo recente a respeito das

${ }^{23}$ Tradução de Maria de Fátima Sousa e Silva (1988, p. 57). 
mais variadas visões sobre a posição de Aristófanes no debate político ateniense é dado por Rosenbloom (2014, p. 304), mostrando o amplo leque de possibilidades levantados pela crítica especializada:

In recent scholarship, the relationship between democracy and Old Comedy has been the subject of debate in which no clear consensus has emerged (see Olson 2008). The best-known fifth-century comedian, Aristophanes, occupies every position on the sociopolitical spectrum. He is a radical democrat and follower of Hyperbolus (Sidwell 2009), one of the "constituent intellectuals of the democracy" (Henderson 1990: 272; cf. Carey 1994), an internal social and political critic who sought to prevent popular self-deception (Ober 1998: 125), a conservative poet working in a genre that manifests a "right-wing bias" and a Cimonian aristocrat disgruntled with the exercise of mass power at Athens (Ste. Croix 1972: 357). (ROSENBLOOM, 2014, p. 304).

\section{A democracia, a igualdade de discursos e o vocabulário dramático}

Muitas outras relações poderiam ser traçadas entre o discurso de Cléon em Tucídides e a comédia ática antiga, mas, se voltarmos à citação do fragmento de Êupolis no início e refletirmos sobre essas relações entre o ridículo e o regime democrático, encontraremos em um termo específico uma questão importante, qual seja: a igualdade

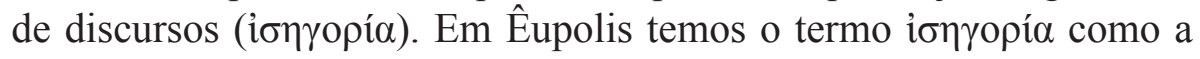
primeira característica da Atenas contemporânea, enquanto em Tucídides vemos como Cléon condena não diretamente a igualdade de discurso, mas as consequências dessa prática: a emergência de oradores, ao seu ver, falaciosos. Isso aparece mais claramente delineado na sequência do seu discurso, em mais uma crítica ao demos ateniense (Tuc. 3.38. 4):

E sois vós os culpados por esses certames mal concebidos por estardes habituados a ser espectadores de palavras, e ouvintes de feitos, vendo os futuros feitos, por aquilo que ouvistes dizer habilmente como sendo praticáveis, mas já quanto a factos realizados, 
não tomando em conta o que foi feito de maneira inegável, negais acreditar no que foi feito por ser mais fiável pelo que vedes do que pelo que ouvistes, mas por influência dos que o valorizam pela arte da palavra.

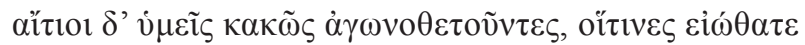

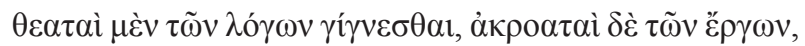

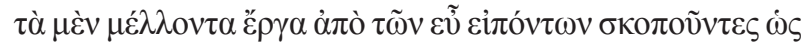

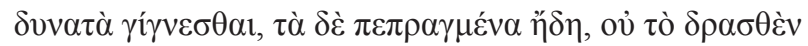

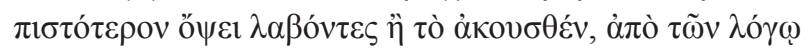

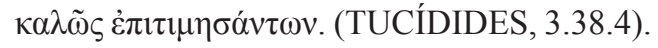

A crítica de Cléon incide sobre a engenhosidade desses oradores, já caracterizados anteriormente como $\delta \varepsilon \xi i ́ o ı ~ e ~ \sigma u v \varepsilon \tau o ́$, e sobre a maneira como eles são capazes de manipular os fatos de forma a convencer os ouvintes de modo mais eficaz do que se estes tivessem visto por eles

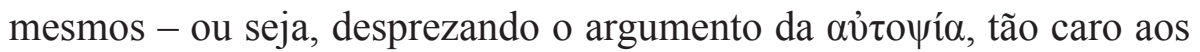
historiadores como Heródoto e Hecateu. $\mathrm{O}$ vocabulário utilizado nessa passagem se relaciona com o léxico teatral em muitos sentidos, como a equivalência de conceitos como "espectadores" ( $\theta \varepsilon \alpha \tau \alpha i)$ e "certames" (áyóv), aludidos nesse trecho, utilizados tanto no âmbito dramático como no retórico. Dessa forma, os espectadores que presenciam esses discursos, sendo facilmente convencidos por eles, são comparados a

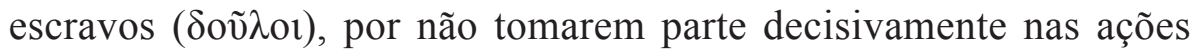
deliberadas nas assembleias (3. 38.5-7):

Estais destinados a ser enganados por um discurso oportunista e a não querer seguir o que está comprovado, sendo escravos do que não se pode realizar e sentindo desprezo pelo que costuma acontecer. Cada um de vós só pode querer ser orador, e caso assim não seja, bater-se com os que dizem coisas desse gênero, para não parecerdes ficar atrás nas agudezas de opinião, aplaudi-los antes que a palavra saia das suas bocas, sendo rápidos a pressentir o que vai ser dito e lentos em prever o que dali vai resultar, pois procurais, por assim dizer, qualquer coisa de diferente da realidade em que vivemos, 
dando pouca importância ao que na verdade existe. Em poucas palavras: sendo vencidos pelos prazeres do ouvido, sois mais parecidos com os espectadores sentados em certames de sofistas do que com homens que tentam solucionar os problemas da cidade.

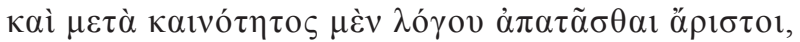

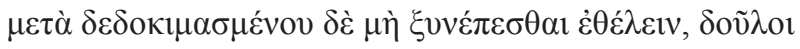

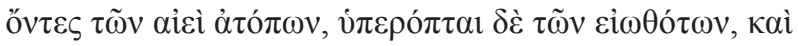

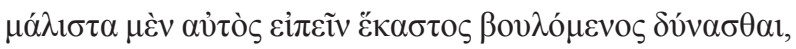

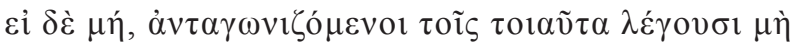

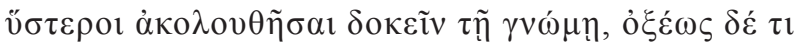

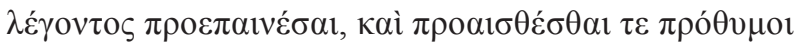

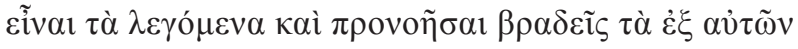

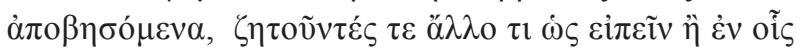

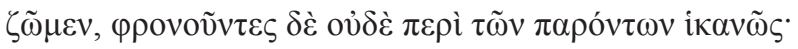

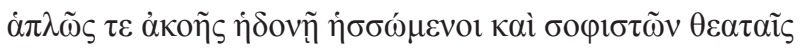

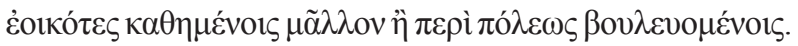
(TUCÍDIDES, 3.38.5-7).

Assim como Atenas é comparada à tirania no começo do seu discurso, assim também os habitantes da cidade são comparados a

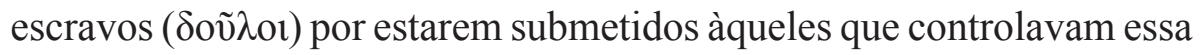
real tirania - os que, segundo Cléon, tinham a habilidade de manipular os sentimentos e pensamentos dos ouvintes por meio das palavras. ${ }^{24}$ Mais uma vez, agora de forma mais explícita, o orador que pragueja contra essa determinada classe, utiliza o vocabulário dramático para deixar mais claras as suas ideias, já que de novo são "semelhantes a espectadores

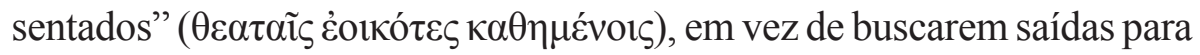
os problemas da cidade. Isso é devido sobretudo a se deixarem enganar

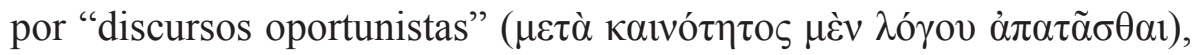
mas o que está implicado nesse caso é mais a noção de discursos

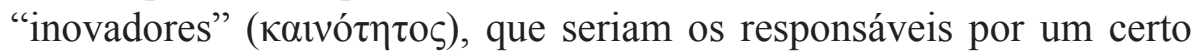

\footnotetext{
${ }^{24}$ De forma aproximada, em Vespas, Filocléon se coloca na posição de um rei, quando na verdade funciona como um escravo dos demagogos, sobretudo Cléon, como demostra ao longo da peça seu filho Bdelicléon, que deseja curar o pai de sua loucura.
} 
encantamento dos ouvintes. Nesse sentido, o discurso de Cléon, mediado obviamente pelas ideias de Tucídides, mostra uma aversão conservadora às novidades, o que pode ser visto também na comédia (sobretudo em Nuvens) - ao mesmo tempo em que encontramos no gênero cômico uma exaltação da originalidade, mais uma vez evidenciando a polissemia dos termos no contexto dramático. ${ }^{25}$ Para Wright (2012, p. 81) essa visão da inovação como algo perigoso reflete uma visão comum sobre Atenas naquele período, sobretudo devido à influência dos sofistas, e revela ao mesmo tempo a posição conservadora de Tucídides:

Novelty emerges as a bogus quality which is contrasted with genuine virtues (good sense, logic, or 'anything normal'); it is also associated with the suspected 'cleverness' of the sophists. The most notable feature of the speech, though, is its tone of open condescension or contempt for the Athenian masses who slavishly admire novelty: this tone chimes in with an attitude which is expressed or implied several times in comedy. Thucydides is a conter-cultural elitist, whose rejection of novelty (along with other superficial or transitory concerns) is part of his overal commitment to abiding literary value and the praise of posterity. [...] A related idea, in Thucydides and elsewhere, is that novelty - in politics, in morality, in every day life - may actually be dangerous. What we call 'novelty' may actually be a transformation for the worse. (WRIGHT, 2012, p. 81).

O uso do termo kaıvó $̧$ na poesia cômica aparece recorrentemente no mesmo contexto do termo $\delta \varepsilon \xi$ iós, já discutido anteriormente, e traz, assim como o outro, uma polissemia difícil de ser sintetizada com segurança, por vezes aparecendo como uma qualidade positiva por vezes perigosa, como vemos em Tucídides. Evidentemente os alvos aqui são os oradores que eram vistos como uma novidade danosa à sociedade

${ }^{25}$ Sobre a questão da originalidade exaltada na composição cômica, e as comuns acusações de plágio ou colaboração entre os poetas, cf. Halliwell (1989, passim); contra Sidwell (1993, passim). 
democrática, mas também os poetas muitas vezes se encaixavam nessa categoria mais ampla de uma geração nova de intelectuais, que também tinha uma função pedagógica, e talvez o exemplo mais claro disso seja Eurípides - sobretudo pela forma como ele aparece no registro cômico (em Aristófanes com maior destaque em Tesmoforiantes e Rãs, nessa última em oposição ao caráter mais tradicional identificado com Ésquilo). ${ }^{26} \mathrm{~A}$ aversão de Tucídides à novidade fica mais clara no uso do

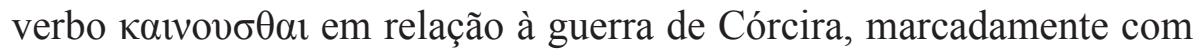

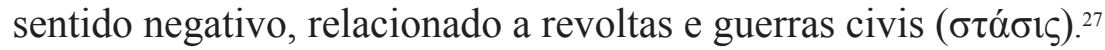

Essa reação efusiva contra as habilidades nocivas de alguns oradores, e talvez poetas, em que o discurso de Cléon se baseia, deve ser obviamente compreendida como uma (re)formulação feita por Tucídides, a partir de opiniões pessoais já negativas a priori sobre o político. É evidente a repulsa do historiador por Cléon, ficando claro isso ao se comparar com os raros julgamentos explícitos que ele faz sobre seus personagens. De Bakker (2013, p. 26) faz um levantamento dessas avaliações explícitas em Tucídides, estando entre as negativas Cléon e o siracusano Atenágoras $(4.21 .3 ; 6.35 .2)$ por suas características

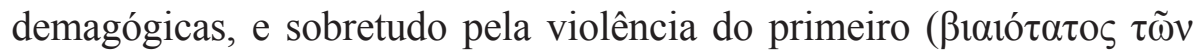
$\pi \mathrm{o} \lambda \imath \tilde{\omega} v)$. Enquanto isso, estavam entre os julgamentos positivos nomes como Péricles (1.139.4) por "ser o mais capaz em falar e agir" ( $\lambda \varepsilon ́ \gamma \varepsilon ı v \tau \varepsilon$

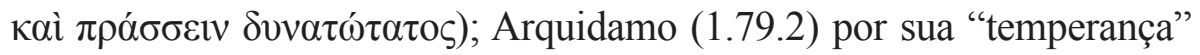
(бофробúvๆ); ou ainda Hermócrates (6.72.2), Frínico (8.68.3) e Teseu

\footnotetext{
${ }^{26}$ Assim como o termo $\delta \varepsilon \xi$ ló $\varsigma$ é caracterizado por Silk como uma das características

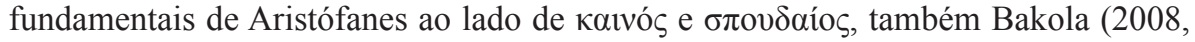
p. 8) localiza o conceito אaıvó $\varsigma$ como um dos fundamentais para a compreensão da

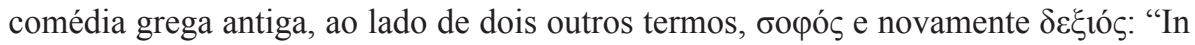
spite of his adherence to the older values, Aristophanes is not resistant to the new critical ideas. On the contrary, while he constructs the moral and social aspects of his persona by evoking postures of archaic lyric poets, he also informs them with literarycritical ideas of his own time. In particular, he makes persistent claims that his reform of the genre is largely due to his cleverness with words, sophistication and innovation [...]. The key words in these repeated claims are dexios (clever, sophisticated, witty, striking), kainos (innovative, original) and sophos (wise, skilled, artistically excellent)". ${ }^{27}$ Cf. Hornblower (1991, p. 482-483).
} 


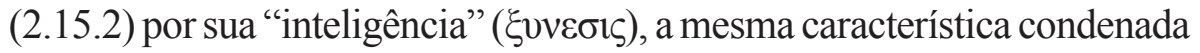
por Cléon nos oradores, aqui exaltada por Tucídides em diversos outros comandantes que ele admira, sendo ele também de estirpe militar.

Assim, a polissemia dos termos que é característica marcante do discurso cômico aparece também delineada explicitamente no discurso historiográfico, como se pode notar dos usos feitos de alguns termos por Cléon, e como eles aparecem reconfigurados ou aplicados de forma distinta em outros momentos por Tucídides. Nesse sentido, em outra passagem do livro III, um tanto após o debate sobre Mitilene, o próprio

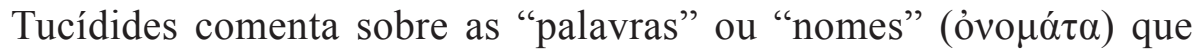

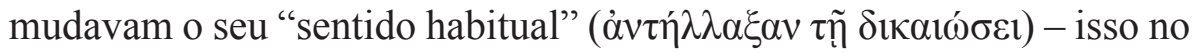
contexto da guerra contra Córcira (3.82.4):

Mesmo as palavras tinham de mudar o seu sentido habitual e adaptarem-se ao que se pensava ser próximo das necessidades. Audácia já irracional passou a ser considerada como coragem fiel; hesitação prudente, refinada cobardia; moderação é considerada como premeditado jogo sem coragem viril; ter visão global das coisas correspondia a ser incompetente em tudo. Avançar freneticamente e de cabeça era considerado digno de um verdadeiro homem; querer decidir com segurança não passava de pretexto bem falante para se escusar.

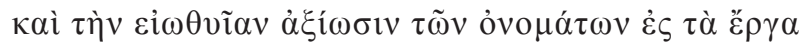

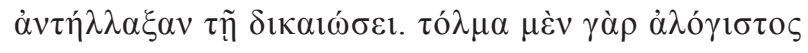

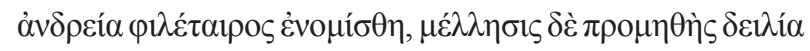

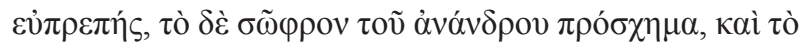

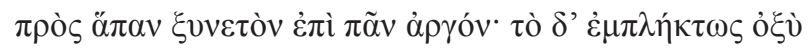

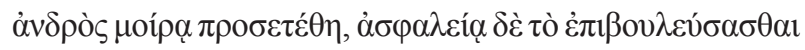

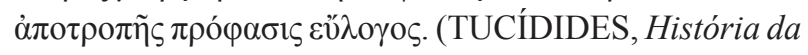
Guerra do Peloponeso, 3.82.4).

O sentido mais imediato que subjaz a essa fala é novamente a lembrança da precaução defensiva de Péricles no início da guerra, e como o povo não compreendeu a sua estratégia em decorrência de uma ânsia de ação - tomando a hesitação "prudente" ( $\sigma \tilde{\omega} \varphi \rho o v)$ por "covardia"

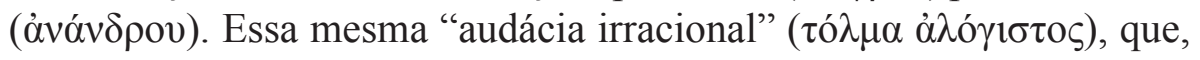


no momento da guerra de Córcira, era considerada como "coragem" ( $\alpha v \delta \rho \varepsilon i ́ \alpha)$, é a imagem exata da caracterização de Cléon, como visto antes: aquele para o qual a reflexão ponderada levava à paralisia da população, e a uma condição de quase escravidão. O que o demagogo pretende é justamente a inversão do sentido usual das palavras, e como notado, essa nova forma de conceber as virtudes estava sendo aplicada naquele exato momento, já que aqueles, como Péricles, que tinham uma "visão global" (

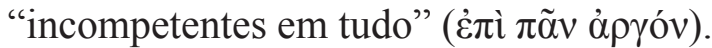

\section{0 caráter risível de Cléon para além dos palcos}

Por fim, ainda sobre as impressões do autor/narrador da obra, é interessante constatar, seguindo Sebastiani (2012, p. 84-85), que das únicas três vezes que Tucídides trata do riso $(3.83,4.28$ e 6.35) este é "sempre inerente a contextos de escárnio e derrisão" e ainda que "é

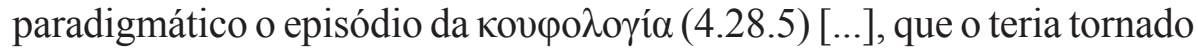
alvo de escárnio público". Nesta passagem (4.28) temos uma cena emblemática de Cléon em apuros diante da assembleia, tendo o político se oposto ao acordo com os espartanos em Pilos (425 a.C.). Como a sua estratégia resulta em dificuldades para o exército ateniense, ele propõe que se enviem inspetores para averiguar a situação, e a população decide enviar o próprio Cléon. Livrando-se do fardo, o demagogo indica Nícias, ${ }^{28}$ seu inimigo político, para o comando da expedição, o que é rechaçado, tendo enfim que aceitar o próprio Cléon o comando. Ao verem a situação de embaraço deste, as pessoas que assistiam à assembleia "caíram na

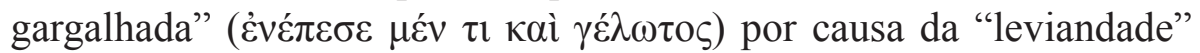

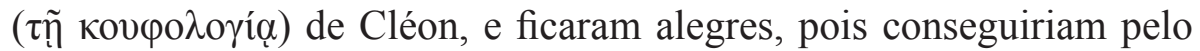
menos um de dois de seus desejos: ou ficariam livres dele - o que,

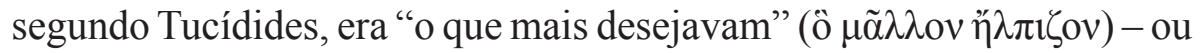
capturariam os lacedemônios, se ele fosse vitorioso.

Sebastiani (2012, p. 83-93) utiliza essa passagem, contrastada com versões de outros historiadores, como Heródoto, Políbio e Tito Lívio, para comentar a noção do "riso exemplar" na historiografia

\footnotetext{
${ }^{28}$ Essa troca de comando na expedição e a entrega do cargo por parte de Nícias parecem ter sido tema de uma comédia de Teléclides (fr. 44 K-A).
} 
antiga. Mas assimilando essa passagem, que é uma das raras vezes em que Tucídides comenta sobre o riso, à produção cômica contemporânea, podemos refletir sobre essa faceta ridícula de Cléon, exagerada na comédia, mas presente também, en passant, na historiografia. Assim como Sócrates não é motivo de riso apenas em Nuvens,${ }^{29}$ mas também em muitos momentos dos diálogos platônicos, sobretudo por sua aparência bizarra, careca, ao andar descalço e se abster de comer, talvez também Cléon não fosse apenas para a comédia uma personagem hilária, "frágil e

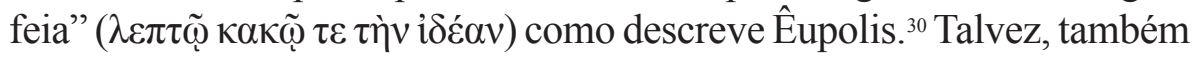
em Tucídides, possamos conjugar a sua grande ferocidade ( $\beta 1 \alpha \iota$ ó $\alpha \tau$ ○ $\tau \tilde{\omega} \nu \pi \mathrm{o} \lambda \iota \tilde{\omega} \nu$ ) a uma personalidade tão inexperiente quanto ousada, que volta e meia poderia estar sujeita ao riso da população, e não por acaso seria um ótimo exemplar daqueles personagens largamente atacados

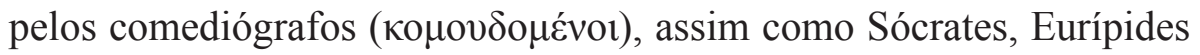
e outras personalidades.

\section{Conclusão}

Com este trabalho, tentei demonstrar, tomando como paradigma a figura de Cléon, de que forma gêneros tão distintos como a historiografia e a comédia ática podem ser comparados: de que modo se interseccionam e de que modo destoam um do outro. Tomando como corpus principalmente o discurso de Cléon sobre Mitilene reconstituido por Tucídides, podemos notar uma série de afinidades na forma como o historiógrafo constrói a figura do político, sobretudo no que diz respeito à violência deste e ao perigo que ele representava para a população ateniense, o que vai no mesmo sentido da descrição que encontramos no gênero cômico, tanto em Aristófanes como em outros poetas cômicos menos conhecidos como Êpolis, Hermipo e Platão cômico. No entanto, cabe destacar que o próprio Tucídides distingue as suas intenções ao escrever a sua obra

\footnotetext{
${ }^{29}$ E em outras comédias da época também, de autores como Amípsias (fr. 9 K-A) e Êpolis (fr. $386 \mathrm{~K}-\mathrm{A}$ ).

${ }^{30}$ E talvez, assim como Sócrates, suas características físicas contribuíssem para isso,

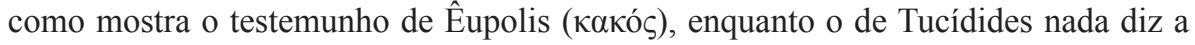
respeito de sua compleição física.
} 
como um legado para a eternidade, daquelas que, como a comédia, eram voltadas para disputas presentes e premiações (Tuc. 1.22.4):

O que escrevi não foi concebido para ganhar prêmios ao ser ouvido de momento, mas como um legado para sempre.

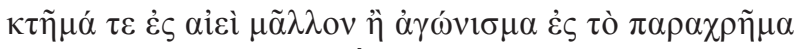

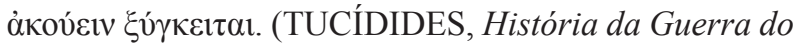
Peloponeso, 1.22.4).

Assim, enquanto o gênero cômico está inserido em um festival e em disputas que têm em vista uma vitória pontual sobre outros poetas, o gênero em que compõe o historiógrafo não se preocupa com traçar uma imagem risível de políticos com fins de agradar a uma audiência. Embora Tucídides não tivesse necessariamente em mente as disputas

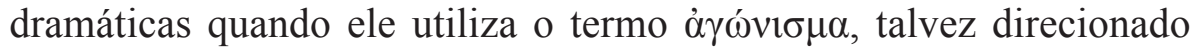
às disputas retóricas, é possível ampliar esse conceito para o universo cultural altamente competitivo que tem como um dos maiores reflexos os festivais dramáticos. ${ }^{31}$ Dentro desses festivais o gênero cômico tratava do mesmo material que ocupou a historiografia: a Atenas contemporânea. E embora as duas manifestações tenham objetivos distintos, alguns personagens parecem não conseguir agradar nem a poetas cômicos nem a generais historiógrafos.

${ }^{31}$ Biles (2011, p. 3), comentando sobre o paralelo entre essa afirmação de Tucídides e o caráter competitivo dos festivais dramáticos, aproxima em certo sentido a posição de Tucídides das parábases de algumas peças de Aristófanes, nas quais o poeta afirma que sua obra também era um monumento para a posteridade, para além das meras disputas por prêmios, como ele descreve as obras de seus rivais: "Thucydides is concerned with historical writing. But even if with the word agōnisma he does not have in mind contests at the dramatic festivals, it is enough that he treats the phenomenon as typifying a set of compositional objectives applicable to any competitive undertaking. In contrast with his own concern for a sophisticated reading audience, for Thucydides the agon, as a cultural paradigm, crystallizes the notion of audience reception in an extreme form, entailing an inescapable demand for authors to anticipate and orchestrate a popular response. As a natural consequence of this, an agonnisma is uniquely bound to an immediate audience". 


\section{Referências}

BAKOLA, E. Cratinus and the Art of Comedy. Oxford: Oxford University Press, 2010.

BAKOLA, E. The Drunk, the Reformer and the Teacher: Agonistic Poetics and the Construction of Persona in the Comic Poets of the Fifth Century. Cambridge Classical Journal, [S.1.], v. 54, p. 1-29, 2008. DOI: https://doi.org/10.1017/S1750270500000555.

BILES, Z. Aristophanes and the Poetics of Competition. Cambridge: Cambridge University Press, 2011. DOI: https://doi.org/10.1017/ CBO9780511779169.

DE BAKKER, M. Character Judgements in the Histories: their Function and Distribution. In: TSAKMAKIS, A.; TAMIOLAKI, M. Thucydides Between History and Literature. Berlin: Walter de Gruyter, 2013. p. 2340. DOI: https://doi.org/10.1515/9783110297751.23.

DOBROV, G. W. Veiled Venom: Comedy, Censorship and Figuration. In: MITSIS, P.; TSAGALIS, C. (Ed.). Allusion, Authority, and Truth: Critical Perspectives on Greek Poetic and Rhetorical Praxis. Berlin: Walter de Gruyter, 2010. p. 359-376.

HALLIWELL, F. S. Authorial Collaboration in the Athenian Comic Theatre. Greek, Roman and Byzantine Studies, Durham, v. 30, n. 4, p. 515-28, 1989.

HENDERSON, J. Demos, Demagogue, Tyrant in Attic Old Comedy. In: KATHRYNA. M. (Ed). Popular Tyranny: Sovereignty and its Discontents in Ancient Greece. Austin: University of Texas Press, 2003. p. 155-179. HORNBLOWER, S. A Commentary on Thucydide. New York: Oxford University Press, 1991. v. 1, books 1-3.

JEDRKIEWICZ, S. Do Not Sit Near Socrates (Aristophanes' Frogs, 1482-1499). In: MITSIS, P.; TSAGALIS, C. (Ed.). Allusion, Authority, and Truth: Critical Perspectives on Greek Poetic and Rhetorical Praxis. Berlin: Walter de Gruyter, 2010. p. 339-358.

NESSELRATH, H. Ancient Comedy and Historiography: Aristophanes Meets Herodotus. In: OLSON, D. (Ed.). Ancient Comedy and Reception: Essays in Honor of Jeffrey Henderson. Berlin: Walter de Gruyter, 2014. p. 51-61. 
OLSON, D. (Ed.). Broken Laughter: Selected Fragments of Greek Comedy. New York: Oxford University Press, 2007.

ROSENBLOOM, J. The Politics of Comic Athens. In: FONTAINE, M.; SCAFURO, A. (Ed.). The Oxford Handbook of Greek and Roman Comedy. Oxford: Oxford University Press, 2014. p. 297-320. DOI: https://doi.org/10.1093/oxfordhb/9780199743544.013.014.

SEBASTIANI, B. B. O riso exemplar de historiadores e biógrafos. In: POMPEU, A. M. C.; ARAÚJO, O. L. de; PIRES, R. B. (Org.). O riso no mundo antigo. Fortaleza: Expressão Gráfica e Editora, 2012. p. 83-93.

SIDWELL, K. Aristophanes the Democrat: the Politics of Satirical Comedy during the Peloponnesian War. Cambridge: Cambridge University Press, 2009. DOI: https://doi.org/10.1017/CBO9780511657382.

SIDWELL, K. Authorial Collaboration? Aristophanes' Knights and Eupolis. Greek, Roman and Byzantine Studies, Durham, v. 34, p. 365-89, 1993.

SILK, M. S. Aristophanes and the Definition of Comedy. New York: Oxford University Press, 2000.

STOREY, I. C. (Ed.). Fragments of Old Comedy: Alcaeus to Diocles. Trad. Ian C. Storey. Cambridge, MA: Harvard University Press, 2011. v. I.

STOREY, I. C. (Ed.). Fragments of Old Comedy: Diopeithes to Pherecrates. Trad. Ian C. Storey. Cambridge, MA: Harvard University Press, 2011. v. II.

STOREY,I. C. Eupolis: Poet of Old Comedy. Oxford: Oxford University Press, 2003. DOI: https://doi.org/10.1093/acprof:oso/9780199259922.001.0001.

WRIGHT, M. The Comedian as a Critic. London: Bloomsbury, 2012.

STOREY, I. C. Eupolis: Poet of Old Comedy. Oxford: Oxford University Press, 2003. DOI: https://doi.org/10.1093/acprof:oso/9780199259922.001.0001.

WRIGHT, M. The Comedian as a Critic. London: Bloomsbury, 2012. 